Wisdom

Wisdom in professional knowledge: why it can be valuable to listen to the voices of senior psychotherapists

\title{
Authors:
}

Marit Råbu, Associate Professor

Department of Psychology, University of Oslo

Postal Box 1094, 0317 Oslo, Norway

Email: mariraa@psykologi.uio.no

John McLeod, Professor

Department of Psychology, University of Oslo

Postal Box 1094, 0317 Oslo, Norway 
Wisdom

\title{
Wisdom in professional knowledge: why it can be valuable to listen to the voices of senior psychotherapists
}

\begin{abstract}
Objective: To explore the nature of professional wisdom, through learning from the experiences of a group of highly experienced senior therapists.

Method: Twelve senior psychotherapists took part in qualitative in-depth interviews about their professional role and their views around a range of aspects of therapy theory and practice. Interview transcripts were subjected to thematic analysis

Results: The analysis yielded nine wisdom themes, clustered within three domains. Each domain represented efforts to resolve dilemmas arising from the experience of being a therapist, around the use of theory in psychotherapy practice, the type of therapeutic relationship that is most helpful for clients, and the experience of therapeutic failure.

Conclusions: Therapist wisdom can be viewed as a form of contextualized knowledge, which functions as a source of emergent insights that arise as responses to the limitations of prevailing ways of thinking. Research into the nature of therapist wisdom draws attention to sources of knowledge within philosophy and the humanities that have the potential to enhance therapy practice and contribute to our understanding of therapist expertise.
\end{abstract}

Keywords: courage, experienced psychotherapists, professional knowledge, qualitative inquiry, wisdom 
Wisdom

\section{Wisdom in professional knowledge: why it can be valuable to listen to the voices of senior psychotherapists}

The practice of psychotherapy draws on multiple sources of knowledge, including personal knowledge derived from life experience and refined through personal therapy, theoretical knowledge consisting of concepts and if-then causal networks that can be used to make sense of complex phenomena, and scientific knowledge comprising propositions derived from critical application of methodological rigor within the context of a scientific community (Bergner, 2006). The domain of professional knowledge represents a particularly important area of therapeutic knowing. Professional knowledge consists of the mix of personal experience and critical incident, conceptual understanding, and practical skills and strategies that have arisen from the process of conducting therapy. Most professional knowledge is communicated through the oral culture of therapy, in the form of stories told by therapists to each other, or within supervision. Within the psychotherapy research literature, there are several different types of study that have evolved in order to capture and disseminate professional knowledge. Professional knowledge is documented in the form of pragmatic case studies that examine the application of professional knowledge within individual cases (Fishman, 1999). First-person autobiographical and auto-ethnographic studies present the accumulated professional knowledge of an individual clinician in relation to a specific client group (for example, Gordon, 2000) or a phase within a career (Robbins, 2006). There have been many qualitative interview studies that have investigated the experience and knowledge of clinicians in respect to discrete areas of practice (for example, Chartas \& Culbreth, 2001; Christianson \& Everall, 2009; Fox, 2011; Karakurt, et al., 2013; Lawrence \& Love-Crowell, 2007; Revell, \& McLeod, 2016; van Rooij, et al., 2012). These studies play a key role within the therapy research literature, both as a means of sharing practical knowledge, and as an alternative perspective to the findings of other types of research, such as randomized trials or 
Wisdom

qualitative studies of client experience (McLeod, 2016).

A further dimension of professional knowledge comprises reflection on the totality of professional experience. Such studies do not focus on specific aspects of the work of a therapist, but instead look at what has been learned across all clients, as well as other facets of a professional role, such as working in an organization, and maintaining work-life balance. This type of inquiry can be characterized as the study of therapist wisdom. Wisdom is a complex, multi-faceted phenomenon that is central to the way in which people make sense of relationships and individuals. Wisdom has been defined as:

....expertise in the fundamental pragmatics of life...The fundamental pragmatics of life refer to deep knowledge and sound judgment about the essence of the human condition and the ways and means of planning, managing, and understanding a good life. (Staudinger, 2008, p. 112);

the "capacity to solve unsolvable problems" (Baumann \& Linden, 2008);

success in creating a good life for oneself while also helping others live better lives (Yang, 2013, p.194).

These definitions reinforce the centrality of wisdom as an element of therapeutic practice: the task of being a therapist certainly involves (among other things) exploring "the essence of the human condition", and helping individuals to create a "good life" for themselves and their families through resolving problems that had hitherto been experienced by the client as unsolvable.

Research into wisdom has made use of a range of strategies. The extensive program of research on wisdom conducted by the Berlin group (Baltes \& Staudinger, 2000) has focused on the task of assessing the extent to which individuals can be considered as "wise", 


\section{Wisdom}

identifying characteristics of wisdom, and examining the extent to which higher levels of wisdom attributes are predictive of success in work roles. This approach conceptualizes wisdom as a dimension of personality or intelligence. There has been some discussion within the Berlin group whether at all aging correlates with growing wiser and the findings are ambiguous (Baltes \& Staudinger, 2000). However, some evidence suggests that if age and facilitative experiential contexts collaborate, older people were found to be wiser (Baltes, Staudinger, Maercker \& Smith, 1995; Staudinger, 1999). Even though increased age is correlated with a decline in "cognitive mechanics", the domain of "cognitive pragmatics", which is viewed to be primarily culture based, can continue to develop under favorable circumstances (Baltes, 1993).

The approach developed by Sternberg (1998) would appear to have particular relevance to the practice of psychotherapy. Sternberg (1998) suggests that wisdom arises from a process of dialectical engagement with core human dilemmas: wise action or thought represents a higher-order mode of understanding that allows apparently irreconcilable arguments or elements to be aligned. From this perspective, wisdom operates as a meaning bridge or metacognitive formulation that provides a platform for making sense of competing beliefs or action tendencies. In therapy, many clients struggle to reconcile fundamental dilemmas ("should I express my anger, or continue to be a person who is popular on the basis of pleasing others?") (Scaturo \& McPeak, 1998). In addition, the role of being a therapist involves achieving a balance between sources of tension such as maintaining a healthy family life, and being available for clients. The notion that therapist wisdom is grounded in the effort to make sense of dilemmas can be found in the influential writings of Karasu (2001) on therapist wisdom. Similarly, the programme of "wisdom training" for therapists, developed by Evans (2015) is oriented around the goal of becoming able to engage effectively with existential dilemmas. Hanna and Ottens (1995) argue that wise therapists are able to arrive at 


\section{Wisdom}

solutions to dilemmas through using a capacity to stand back from the immediate detail of an issue, and make sense of it in relation to multiple implicit contexts from which it could be understood. The practice of "wisdom psychotherapy" is based on interventions for enabling clients to learn how to engage in contextualizing problems (Lieberei \& Linden, 2011; Linden, Baumann, Lieberei, Lorenz, \& Rotter, 2011).

In the first systematic investigation of therapist wisdom, Levitt \& Piazza-Bonin (2015a;b) recruited psychotherapists nominated by their peers as possessing wisdom, and interviewed them about how they enacted wisdom within the process of therapy, and their views around how therapists could become wise. In respect of therapy process, the core category to emerge from this material was: "clinical wisdom is taking the risk not to know: openly exploring clients' ambiguity and vulnerability to intervene within their values and context" (Levitt \& Piazza-Bonin (2015a, p.12). In respect of the role of training in the cultivation of therapist wisdom, the wise therapists interviewed by Levitt \& Piazza-Bonin (2015b) identified three broad themes: (i) encouraging students to be active in exploring knowledge outside their own worldviews; (ii) training that resisted current tendencies in the profession to favor cognitive knowing and the acquisition of techniques; and (iii) commitment to self-care.

It seems likely that studies of clinicians nominated by their peers as "master" therapists (Jennings \& Skovholt, 1999; Jennings, Skovholt, Goh, \& Lian, 2013) or "passionate" therapists (Dlugos \& Friedlander; Miller, 2007), research into the cultivation of therapist expertise (Miller, S., Hubble, Chow, \& Seidel, 2013, 2015), and investigations of characteristics of effective therapists (Anderson, Ogles, Patterson, Lambert, \& Vermeersch, 2009; Nissen-Lie, Monsen, \& Rønnestad, 2010; Nissen-Lie, Rønnestad, Høglend, Havik, Ole Solbakken, Stiles, \& Monsen, 2015) could contribute to an understanding of therapist wisdom, 


\section{Wisdom}

because all these constructs can be viewed as aspects of an overarching dimension of "exceptionality". On the whole, wisdom does not appear to have emerged as a particularly salient theme within this body of work. Jennings and Skovholt (1999) found that the master therapists in their sample expressed a high level of open-ness to complexity, an attribute that has been associated with wisdom. However, findings from other studies in this area have tended to find that the distinctive features of exceptional therapists were that they exhibited open-ness to feedback and learning, willingness to learn from life experience, professional self-doubt, highly developed interpersonal skills, and attention to work-life balance. It may be that therapist wisdom represented an implicit theme in these studies, or that researchers did not employ wisdom as a sensitizing construct or variable. On the other hand, it may be that wisdom is a relatively rare characteristic of therapy practice, or a description that therapists are cautious about applying to themselves (Siegel, 2012).

There do not appear to have been any studies that have directly examined client perceptions of therapist wisdom. In a meta-analytic review of client experiences of therapy, Levitt, Pomerville, and Surace (2016) found that the theme "internalizing the accepting therapist" occurred in 18 out of 109 studies included in the review, and was considered as generally helpful by clients. Although the process of internalization of the therapist can take many forms (Geller \&Farber, 1993), it is possible that for some clients this experience may encompass a sense of being able to access therapist wisdom on an on-going basis in their lives outside of therapy.

It is important to take account of how wisdom functions within the broad domain of professional knowledge. Psychotherapists, and members of other occupational groups, operate within communities of practice - networks of practitioners who continually share knowledge and experience (Lave \& Wenger, 1991; Wenger, 1998). Studies of the functioning of communities of practice have shown that these structures are hierarchically organized, with a 


\section{Wisdom}

small group of expert practitioners passing on their skills and knowledge to less experienced members, who are in an apprenticeship relationship. The knowledge base of a community of practice is anchored in a shared web of tacit and formal knowledge (Polanyi, 1958). This web of practical knowing needs to be continually renewed, in the light of changing external circumstances (e.g., economic restrictions on the length of therapy) and internal developments (e.g., the invention of new techniques). Routine therapeutic practice is largely informed by taken-for-granted or "common sense" ideas about how to proceed. Beyond common sense, there exists a horizon of "received wisdom" that represents new ideas that have been broadly accepted. It makes sense to regard wisdom statements generated by expert members of the community as ideas that questions and reformulate commonsense assumptions, in order to renew or replenish the "received wisdom" of the collective. Viewed in that light, wisdom statements have meaning not as general or universal "truths", but as ideas that function within a particular context.

Taken as a whole, theory, research and clinical experience around the relevance of the concept of wisdom for the practice of psychotherapy suggests that further research into this phenomenon is warranted. Given the limited amount of research into this topic, within the field of psychotherapy, there are many fruitful avenues of inquiry that might be pursued. The study presented in the present paper focus on the experiences of senior therapists within a particular professional context. The rationale for analyzing wisdom within this group is that there exists some evidence that senior psychotherapists, in the closing phase of their professional life, define themselves as have become wiser (Geller, 2014; Goldberg, 1992; Orlinsky \& Rønnestad, 2015; Rønnestad \& Skovholt, 2013). It seems likely, therefore, that an investigation based on this group of therapists might yield richly-described and theoreticallyrelevant examples of therapist wisdom. Given the possibility that wisdom may be culturally and historically contextualized, it is appropriate to select informants from a specific social and 
Wisdom

cultural setting. In the light of these considerations, we decided to analyze the nature of professional wisdom in a group of highly experienced therapists in Norway.

\section{Method}

To ensure that the views of participants could be represented in a manner that was faithful to their personal experience, we used open-ended interviews that were analyzed through a method of qualitative thematic analysis (Braun \& Clark, 2006; Braun, Clark \& Rance, 2014). Participants were interviewed about their professional role in the broadest sense, including its personal meaning, their view on what good therapy consists of, and how their view of therapy had changed over the years. What the therapists reported about the impact of working as a therapist on their personal life is available in Råbu, Moltu, Binder and McLeod (2016). As with other qualitative studies (see, for example, Levitt \& Piazza-Bonin, 2015a; b) in order to represent rich qualitative data in sufficient detail, it is necessary to publish separate papers on different themes. None of the themes discussed in the present paper were mentioned in Råbu, et al. (2016).

Openness to the possibility of being surprised by finding something else or something more in qualitative data material than was first expected, are valued aspects of the process of conducting qualitative research (Elliott, Fischer \& Rennie, 1999; Kazdin, 1999; Magnusson \& Marecek, 2015; Marecek, Fine \& Kidder, 1997). In the present study, wisdom themes were therefore implicit in both the interview conversations and transcript data, but became apparent as a central character of the findings during the process of data analysis. This process, in which wisdom appeared as an emergent property of the data, underscores the distinctiveness of the sampling procedure in the present study. Unlike Levitt and Piazza-Bonin (2015a,b), participants were not selected on the basis of having a reputation for being wise and were not explicitly invited to reflect on the topic of clinical wisdom. In the present study, we were able 
Wisdom

to see in retrospect that wisdom themes were implicit in the phase of planning and interviewing, but they did not represent a priori aspect of the initial design of the study.

\section{Sampling}

Our aim was to gather a sample of senior therapists able to look back and reflect on various aspects of psychotherapy after a long career as a practicing therapist. Formal lists of active professionals do not include information of age and details of years of experience. Because the population of psychotherapists in late to very late stages of their career living in and near the city in which the study took place is fairly limited and we wanted to conduct the interviews face to face, we used a procedure of snowball recruitment (Kuzel, 1999; Patton, 2002). This was useful to allow for a sample of enough participants to explore our research questions across different accounts. Our strategy involved first inviting two therapists known by reputation to the primary researcher. They were chosen based on the knowledge that their primary occupation had been active work with clients and that they were in an age where they had retired or were on the point of retirement. We did not distinguish between completely retired and still working therapists, since it is apparent that many aging therapists scale down their practices very gradually. After their interview each informant was asked for recommendations of further therapists in the similar age and situation which might be eligible to take part in the study. We found that individuals who had already been interviewed were suggested again by those who were interviewed later; nine of the informants were suggested twice or more by other therapists. A total of nine suggested therapists were not invited because they; a) were married to a former informant (two), b) were younger than 68 years, (two) c) lived far from Oslo and therefore were harder to reach (two) or d) the interviewer knew him/her in a very personal way (three). That the therapists to a great extent seemed to suggest each other may mirror that they are drawn from a rather limited group of therapists. 
Wisdom

Eight invited therapists refused to be interviewed. According to our ethical protocol, informants were free to refuse to take part without stating any reason. As a consequence, we do not have information about why some therapists refused to be interviewed, or if this group was different from those who volunteered to be interviewed.

The methodological framework adopted in this study does not make any specification of required sample size (Braun \& Clarke, 2006). We continued to recruit participants until we achieved sufficient heterogeneity with respect to demographic characteristics (career paths, theoretical modality, gender, marital status, present work load) and saturation of analytic themes.

\section{Procedure for data collection}

The therapists were invited successively with a letter that described the study, and later a follow-up phone call. They were informed that we were basically interested in how being a therapist had influenced their personal life (anonymous reference). The therapists were interviewed face by face and one at a time by the first author. They could choose where they wanted the interview to take place. Five were interviewed in their own office, four in their home and three in the interviewer's office. The interviews lasted about one and a half hours (ranged from 75 to 130 minutes).

The interview guide was based on analysis of issues identified within the existing research literature. Interviews were semi-structured and designed to enable participants to reflect on all aspects of their working and personal lives (see Appendix). When we look back, we can see that several of the interview questions indirectly invited informants to share wisdom, even if wisdom was not an explicit focus beforehand. For example they were asked about their views about what therapy can offer, what they thought of as the most important qualities for a therapist, and if and how their views have changed over the years. The interviewer used the interview schedule as a starting point for an open dialogue with the 
Wisdom

participants, in which they were encouraged to provide concrete examples and narratives from practice. The order and formulation of the questions were handled in a flexible way, but the interviewer made sure that all the questions where touched upon during the interview. The interviews were audio-recorded and transcribed verbatim by the interviewer.

\section{Participants}

The participants were twelve highly experienced psychotherapists including seven women and five men. Their ages ranged from 68 to 86 years (mode and median 74). Nine were psychologists and three were psychiatrists. They had worked as psychotherapists for between 35 to 56 years (mode 41, median 40). Four started up in other professions but changed careers after few years, and had their main career as a therapist. For eleven of them clinical practice as a psychotherapist had comprised their main occupation. One had worked as a researcher and teacher in about equal combination with being a therapist. All of the therapists had combined being a psychotherapist with doing research and/or teaching and supervising for periods of their life. At the time of the interview, all lived in or near Oslo, the capital of Norway. Ten of them were of Norwegian heritage. Two grew up and were educated in other European countries and later moved to Norway where they had their primary work experiences. All had to some degree a psychodynamic starting point, which reflects the tradition in Norway about 40 years ago, and they had developed in different directions during their professional life. Ten of the therapists still, more or less, identified themselves with psychodynamic theory. Of these, their views on psychodynamic therapy varied to a great extent. Typically they underlined that they had grown more integrative over the years, that they were critical towards aspects of psychodynamic theory, and that they found other perspectives, such as for example systemic theory and cognitive therapy, useful as well. Three participants described psychoanalysis as their primary perspective on psychotherapy. One described himself as an "apostate" and another based her work on emotion- and 
Wisdom

developmental perspectives. The therapists had during their life worked in several different clinical settings within the public mental health care system in Norway. All but one of them had their last part of their career in a publicly funded private practice. They had worked with a wide variety of client groups. By definition these therapists are in a rather limited group who were able to attend higher education in the 1950s and 1960s, which meant that they were drawn from a relatively prosperous sector of Norwegian society. At the time of the interview, five of the therapists had retired completely. Of these, two still carried out voluntary work and offered supervision. Five were about to scale down their practices and worked part-time as therapists. Two still worked full-time, but were intending to scale down; one of them planning to retire completely within few months.

\section{Researchers}

An initial thematic analysis of the entire data set from interview transcripts was conducted by a team of four researchers (Råbu, Moltu, Binder \& McLeod, 2016). Transcript segments categorized thematically as referring to examples of therapist wisdom were then analyzed in more detail by two members of the team (the authors). Both the authors are psychologists and researchers working in a university setting. They combine research with teaching psychotherapy and research methods to psychology students and work part-time as psychotherapists. Both the authors have an interest in qualitative research into processes of change in psychotherapy, and have backgrounds in relational, dynamic, humanistic and existential psychotherapy and psychotherapy integration. We did not read or discuss the literature on therapist wisdom until after we had completed data analysis. The key paper that provided us with our initial access to this literature (Levitt \& Piazza-Bonin, 2015a) was published after we had completed our first analysis. One of the authors is Norwegian, while the other is from Scotland. All relevant transcript material was translated into English. 
Wisdom

The interviewer had some years earlier had some contact with three of the informants in professional contexts. Two of these were the first to be invited, and the third happened to be suggested by another informant. Further, the interviewer knew six of the informants by name and reputation. Three of the informants were completely unknown to the interviewer beforehand. In terms of background knowledge, our approach to the interviews was informed by extensive reading of the literature on therapist development, in which the concept of wisdom receives relatively meagre attention. We expected that people with about forty years of clinical experience each would have stories to tell which would be deeply relevant for our research question.

The interviewer kept a diary for immediate impressions and reflections after the interviews and after the transcriptions. The purpose of the diary was to note contextual information, possible meaningful features not otherwise captured or not yet understood, to write down preliminary thoughts on the analysis. This material was used to enhance researcher reflexivity (Alvesson \& Sköldberg, 2000) and as a background information for the other researcher.

\section{Ethics}

The study was approved by the Regional Committee for Medical and Health Research Ethics (Region South-East) and the Norwegian Social Science Data Services. Private details (names, places) were omitted from the transcriptions and details of the participants have been changed to provide anonymity.

\section{Analysis}

We performed a thematic analysis of the material, guided by the principle that "a theme captures something important about the data in relation to the research question, and represents some level of patterned response or meaning within the data set” (Braun \& Clark, 2006, p. 82). We needed to try to convey the wisdom in the way they told their story, and to 
Wisdom

sort out their understandings of the complexity of psychotherapy. Therefore we chose to use examples and longer excerpts from the material to "bring out their voices". Even if the therapists had many wise things to say about life in general, we concentrated on themes relevant for the practice of psychotherapy.

Information about the initial analysis of the entire interview data-set can be found in Råbu, Moltu, Binder and McLeod (2016). This initial analysis was conducted by a team of four researchers, and resulted in four themes: it has been a privilege to know and contribute, and to be allowed to grow personally; facing suffering and destructiveness has been a burden; being a therapist has had an impact on my personal relationships - for better and worse; I have needed to construct a way of living that allowed me to continue to do the work. Therapist wisdom emerged as a superordinate theme at that stage. The material that was specifically categorized as relating to therapist wisdom was then analyzed in detail by two members of the team (the authors of the present study). We first read through the transcribed material to develop a basic sense of the overall content. Then, both researchers separately carried out initial segmenting and coding, identifying significant narratives and suggesting possible themes. Passages of text that appeared to relate to the phenomenon of wisdom were initially identified on the basis that they referred to knowledge or insights about features which may be important, meaningful and complex in the carrying out of psychotherapy, or referred to ideas that questioned and reformulated commonsense assumptions, in order to renew or replenish the "received wisdom" of the collective (cf. Polanyi, 1958). All segments of text that satisfied this preliminary understanding of therapist wisdom were highlighted, regardless of where they occurred in the interview transcripts. The possible meaning of units of text (words, phrases, sentences) were then indicated using provisional codes. The researchers then met and presented and explained their emerging understanding of how wisdom appeared in the material and the suggestion of codes. The narratives and categories 
Wisdom

each had selected were explored and critically reviewed, and revised and refined during several meetings over a 12-month period, before consensus was reached about the presented version. The first author eventually carried out a credibility check by reading through the complete interview material after the analysis was completed. In addition, aspects of the data analysis were presented to groups of colleagues. These procedures resulted in some minor adjustments of the themes. During this process, there were no conflicts or situations experienced as disagreement: the process was very tentative and open for an extended period.

The therapists are labeled with letters from A to L; the contribution of informants to each theme is indicated in Figure 1 below.

\section{Results}

The wise statements embedded within the discourse of these experienced psychotherapists, reflected a general over-arching theme that could be characterized as "resolutions of core dilemmas arising from the experience of being a therapist". Within this over-arching core theme, the analysis generated 9 specific wisdom themes, clustered within three superordinate themes or domains.

\section{Figure 1 here}

In the interviews, wisdom was contextualized within accounts of how the informant had struggled to come to terms with core dilemmas associated with the role of psychotherapist. In the following sections, in order to reflect the emergent quality of wisdom statements, detailed examples are provided of stories told by therapists within each of these themes.

Domain 1. Wisdom arising from the struggle to resolve dilemmas associated with the use of theoretical knowledge in psychotherapy practice

The therapists interviewed in the present study endured a professional era marked by on-going fundamental debates around the role of theory in practice. These debates have 


\section{Wisdom}

centered on a number of issues, including the relative validity of competing models of therapy, and the balance between theoretically-guided practice as against a more pragmatic or intuitive approach. We identified three wisdom themes in this area: (i) psychotherapy theories become more helpful as you really get to know them; (ii) there is always another truth; and (iii) being clever is not the same as being helpful.

Several of the therapists, especially those who had kept a psychoanalytic perspective, felt that they had grown more fully into the theoretical ideas that they used in their practice: Some of what I think has been helpful, and which has also helped me much in therapy, has been a gradually increasing understanding of transference - counter transference processes. Over time it became clearer to me. It took some time before I got a real faith in it, perhaps. But, when it first has become a reality to me [....] things that had been harder earlier became more of an interesting challenge, then. (Therapist D)

My relation to theory has not exactly changed, but instead taken up more space. When you think, yes, you have to listen, be empathetic listening, and then you have like, when you start up, then you have an idea of what that is. But eventually it takes on a much larger dimension, how to listen and what to listen for. It's as if you learn it at first just theoretically and in supervision, and later it become more and more ones' own, you experience it, you suddenly realize, yes, but that's it, yes!... It becomes a part of oneself, and more a matter of course. (Therapist B)

For these informants, the first stages of theoretical learning seem to have been somewhat detached from their lived experience. Later, in their careers, the same concepts seemed to have taken on a quality of being genuinely understood and integrated, and as a result more helpful in terms of informing practice.

At the same time as growing more fully into theory, the therapists in the study also became more skeptical and pragmatic in their attitudes to theory. Most of these therapists 


\section{Wisdom}

reported that they had learned to view theories from a perspective that different theories are useful in different ways, and that none of them fully captures the truth. Ten of the therapists still, more or less, identified themselves with psychodynamic theory. Of these, their views on psychodynamic therapy varied to a great extent. Typically they underlined that they had grown more integrative over the years.

I'm pragmatic, I find no salvation in any theory. (Therapist L)

I used to have a stronger belief in what was written in the books I read ..., in a sense, from the textbooks... I was part of that discussion when systemic theory was introduced in Norway, I was part of it from the start, and yes, that was the truth. But anyway, there's always also another truth. Or the discussion of psychoanalytic theory against cognitive. But then you get like that only "one theory is the whole truth, and all others, they have not understood anything". That attitude is just arrogance and omnipotence. It is very widespread, and it comes out very evidently in such discussions. And then you get the battle between the different directions.... I believe a therapist should learn to understand more. Like, on the one side, and on the other hand etc. ... I think that in general, among the colleagues I talk to who are the same age as me, we become less loyal to books or theories and a little better at being adaptable. (Therapist A)

The attitude that "there's always another truth" did not appear to mean, for these therapists, that theory was of no value at all. Instead, what was conveyed was that there was no single theory that could provide all the answers (or "salvation").

A third theme within this domain of wisdom was related to the potential dangers associated with theoretical over-confidence. Several of the therapists described how they had learned, over the course of a career, to develop the capacity to relate to others and hold back 


\section{Wisdom}

their tendency to be clever. Cleverness was not helpful to others. Cleverness placed one in danger of becoming grandiose or omnipotent. One therapist described that he in his early career thought about psychotherapy as a kind of detective work, where one should be clever and put together missing pieces. Several of the therapists talked about how they had had to liberate themselves from the wish to understand everything and be too clever in the relationship. They reflected on what may be lost in cleverness; we can think of the capacity to deal with uncertainty, vulnerability, tenderness, emotions, and recognition of limitations. The following quote is from one of the psychiatrists in the sample:

I think many doctors are the kind of people who feel very strongly that they have a need to help others, and on the other hand, a kind of need to achieve something too, that there is such a mix; that I need to help and I need to master. And I think that it is, at least for physicians, that it is to some extent a kind of a selection criterion, or what directs many into this career path. But when it comes to psychotherapy... it requires a very different kind of involvement or trajectory than that which occurs for example in medicine. When it comes to psychotherapy I think it's more about the ability to be present and to give space for the other person. And that, I think, is a little different from the way it is in medicine in general. Brilliant cleverness often does not leave much space for others, it allows first and foremost for one's own perfectionism. (Therapist D)

Other interviewees talked about the importance of learning to hold back the urge to be viewed as clever by the client.

What we see, in the material summarized and displayed in this section, is the emergence in these therapists a wise approach to the use of theory. Theory is not just a matter of cognitive understanding - it takes time and experience to truly appreciate the meaning and implications of theoretical constructs and models. Theory is fluid - there is always an 
Wisdom

alternative theoretical perspective available, which may be more (or less), illuminating.

Finally, it is possible to lose one's way in relationships with clients through being too clever, in the sense of using theory to dominate and impress others.

\section{Domain 2. Wisdom arising from the struggle to resolve dilemmas concerning the type of therapeutic relationship that is most helpful for clients}

All of the participants in the study talked about the challenge of developing productive relationships with individuals whose life experience had lead them to lack trust in others. Implicit in their accounts of this struggle was an acknowledgement that existing ways of understanding the therapeutic relationship, though valuable, were not quite sufficient to provide a complete guide to how to proceed in respect of this aspect of therapeutic work. These therapists were not able to articulate their understanding of the therapeutic relationship in a neat, packaged manner, for instance as a model, concept or aphorism. Instead, individual participants offered descriptions of different aspects of an emerging shared wisdom around this topic. The essence of this wisdom appeared to be based in a sense of the need to accept oneself as a different person from the other person in order to be in a true dialogue with another and to really take part in a relationship. The clearest statement of this understanding came from therapist B:

.....the most difficult cases, and patients with very early, deep injuries, in cases where it also appeared a very strong negative transference that I struggled to handle, and have needed help from colleagues to deal with [are those] I feel I have learned much from. Perhaps they have taught me [...] that one must have both a space for oneself and a space for the patient $[\ldots .$.$] with this kind of patients; they live within you... I think one$ important aspect is to have an inner boundary and to keep an inner space for oneself. [...] you are sitting on your chair, and I'm sitting on my chair. We do not sit in the same chair (laughs). 
Wisdom

In our analysis of this aspect of the interviews, the idea that it is helpful to create "a space for oneself and a space for the patient" emerged as a core principle by which these therapists operated. The implications of this principle could be seen to be connected to other aspects of the therapist role.

One important consequence of cultivating the "difference between you and me" was that it made it possible for the therapist to be trustworthy, through showing the client real interest and engaging in their life in an active and authentic manner: "the key to being a good therapist is that you can trust the person. If the therapist is not trustworthy, then nothing works" (Therapist $\mathrm{H}$ ). The idea that trust was built on a willingness to be visible to the client, as a person, was expressed more fully by therapist G:

I think it is important to be very personal in relation to patients. Not private, but personal. That you have to expose yourself as a human being, as a person. I have especially learned that in relationships with psychotic patients. There is no use in any therapeutic tricks, or to hold back anything. Then you must be direct and clear as a human being and person. And I have probably carried this with me and been aware of it, in the clinic and in other contexts, so I'm probably a pretty active person in relation to patients, and am not afraid to be spontaneous.... It is more harmful to be passive, I think. Often the things you do which are wrong is to not do anything; that you refrain from saying anything, if you are just holding back and rarely sharing your feelings. It is actually allowable to expose affect when facing your patients. Simply. And I think that just might be therapeutic. So at least in that area I can see that I have developed and it has made me feel much more confident.

Here, therapist $\mathrm{G}$ appears to be referring to a learning process across the course of his career - he became more willing to be "personal", in the sense of constructing a "space for 


\section{Wisdom}

himself" within the relationship with his clients, he became more active and emotionally available to them, and discovered that this stance was therapeutic, which in turn gave him confidence that it was the right thing to do.

The wisdom that these therapists had been able to accumulate over the course of their careers, around their understanding of how to facilitate a helpful therapeutic relationship, was grounded in their use of the metaphor of client-therapist relationship as a "space":

For me, the metaphor is to create a safe space for development for the patient, where it is possible to try out, experiment and explore. (Therapist K)

A key characteristic of such a space was that it represented an arena in which it was possible to be playful:

It is essential if you are to change and to learn, that you need to be surrounded by positive emotions. It is a necessity; this developmental space must be characterized by positive feelings and play. And I define play very wide, then, as a playful and exploratory attitude. [....] It does not mean you do not take what is serious seriously and suffering seriously, that is, all this hard stuff. We know much about that [.... I think that therapy should not be too serious, it should also be fun [....] to laugh together can mobilize a feeling that we are together, and here I can figure things out and this is a safe place to be and here is actually one who will follow me. (Therapist $\mathrm{K}$ )

You must ensure that it is kind of fun in therapy, not only misery and snot and tears. You have to work to get it to be somewhat engaging and somewhat amusing and, therefore. I think so. People who just sit down and accept the misery...it must be absolutely terrible. So being in a dialogue and also, in a therapy relationship, requires that you can also laugh along with the patient in the context of therapy. I think it is quite important. Being a live person.... I think that is important. (Therapist G) 
Wisdom

The version of the metaphor of a therapeutic "space" used by informants in the present study can be understood as a rejection of dominant assumptions within the professional literature that characterize the therapeutic relationship in terms of images of a work space where client and therapist collaborate or a battlefield space in which they ally to combat against a common enemy. By contrast, the "spatial" imagery invoked by informants was of a playground, a space for imagination and enjoyment.

A further element of the theme of cultivating the "difference between you and me" referred to what a therapist needed to do to make it possible to create a space for play, and to function effectively within such a space. In this respect, participation in art was mentioned spontaneously by all but one of the therapists. Several of them performed some kind of art in addition to being a therapist (singing, playing an instrument, painting or drawing pictures). They saw art as an important way to develop their ability to be present with and relate to clients. Relating to art can be a way to get new and different perspectives on life and living. Art represented an important source of knowledge for practice: "I read as much fiction and philosophy as I read psychology" (Therapist J). For several interviewees, involvement in art was linked to willingness to improvise and be creative in their work with clients.

Several of the therapists directly compared performing therapy with artistic activity, that doing therapy has similarities with art or art/craft:

I wish I could have continued to play the violin [he studied music but had to stop due to an acquired hearing impairment]... At the Music College, then, there were singers and musicians and stuff, they were very able to talk about what they experienced when they played. Because playing music is a relational activity, too, very much, and it can initiate very much emotion. Jazz musicians, for example, talk about how they are able to do certain things in music thanks to the other band members, i.e., the others.

(Therapist F) 
Wisdom

I built our cabin by myself. I do it the old fashion way, with my hands and a hammer and such things $[\ldots .$.$] Therapy is also in a way some kind of craft. I think of it as sort$ of both art and craft. It is very much on that creative side. I feel I get to use my creativity as a therapist, to use, what can I say, that artistic part of myself, or the creative part... I can use a creative part of myself when I sit here in the sessions, the way you listen and combine stuff and give feedback. That is very creative work. (Therapist C)

I paint faces [shows me paintings]. And all those faces, I don't know where they come from, if they just come from inside me, or if they in a way are all my patients. And I am not afraid of letting people see my drawings. They are not perfect, or they are not technically good, but... I have gotten more space inside over the years. I have over the years developed more space for myself, and that becomes apparent. (Therapist E) All participants also talked about the value of art and making, alongside other activities such as sport and outdoor pursuits, and family life, as ways of maintain well-being and coping with the stress of therapeutic work. However, active involvement with art and craft was seen to possess an additional benefit, in contributing to the capacity to use imagination and creativity within a therapeutic space.

A final dimension of an appreciation of the difference between "you" and "me" was that it required courage:

...you keep standing when it storms. (Therapist J)

I think I have changed very much; I have become much more flexible. And it was very interesting, for one client came back to me after 10 years, and then she said to me: "Do 
Wisdom

you know what? You are a much better psychologist now than you were 10 years ago." So I have become much more... I dare much more. I'm not like that, just by the book... I have become more tolerant and more flexible and I dare more, dare to say more. I'm not so afraid of doing something wrong. (Therapist I)

As a therapist you should endure crying, endure anger, and tolerate such things. Tolerate aggression directed at you, the therapist. That is a struggle, it's hard. I tolerate it when it comes on, but I notice about myself that I try in a way to prevent it from appearing, which is cowardly, and unhelpful for the patient. Sometimes you have to be confrontational and withstand anything". (Therapist G)

The point being made in these statements is that creating a space that invites the voice of the client, will inevitably create situations in which the client talks and acts in ways that are hard for the therapist to tolerate. At the same time, if the therapist is also in that space, as a person, these actions will have an impact on the therapist, rather than being deflected by professional defenses. This dilemma then generates an awareness of the importance of the moral quality of courage as a necessary aspect of a helpful therapeutic relationship.

\section{Domain 3. Wisdom arising from the struggle to resolve the dilemma of reconciling the ambition of therapy theory with the lived experience of client outcomes}

In the interviews, therapists talked about how their early training had lead them to hold high expectations for the effectiveness of their work with clients, in terms of being able to achieve transformations in basic personality functioning. Most of them reported that their experience in practice had resulted in recognition of the importance of modesty and an awareness of limitations of what it can accomplish:

You need to have the time for moments of realization, where you also can see your own limitations. It may be sad enough, but that's the way it is. I think I had some ideas 
to start with, that through in-depth-therapy, one would really achieve dramatic changes. But I think, it is not exactly the way it is, really. There may be things happening which are, they are not very dramatic when you view it from outside, but they can nevertheless mean an awful lot to the person. I think I probably had some notions that it should be possible to achieve structural personality changes. And, yes, maybe just a little bit, that one sometimes can get to any of that, but otherwise I think that the patients they are themselves and behave in much the same way after therapy as before. (Therapist F)

I probably had an unrealistic expectation about how therapy could change people. Not that I have become more pessimistic, rather more realistic - that therapy can moderate the bad parts and provide some increased self-esteem, self-confidence, and can kind of cause people to be a little more pleased with themselves, quite simply. That they can experience more because they dare to take the risk of exposing themselves more in relationships they have, and see that it's not necessarily dangerous. To expand their life-space, so to speak ... And not least, I believe that therapy can, and that is especially true for the more poor, disadvantaged, and psychotic patients, to get help to see that they are a person that someone can both understand, and also can feel comfortable being with, and enjoy being with. Thus, to be a person that others can enjoy. I think this contributes to a somehow increased self-esteem, and can make them dare to venture and expose themselves more in other contexts... if they experience in the therapeutic relationship over time that I really enjoy their company. That is important, in a way, to convey to them, simply. It is also contributing to getting back a little more faith that they are a person that someone actually can enjoy. (Therapist G) 
Wisdom

What seems to be happening within this domain is a recalibration of expectations regarding what clients can gain from therapy. This learning process comprised two distinct steps. First, it was necessary to accept that many textbook accounts of how therapy operates were unrealistic. This realization opened up the possibility of noticing and celebrating the actual ways that therapy made a difference to clients. Alongside this process, at a personal level participants reported sadness around losing their sense of potency, accompanied by a realization that quite simple things can be facilitative, such as simply conveying to a client that one enjoys their company.

\section{Discussion}

Within the present study, three main domains of wisdom emerged from interviews with senior therapists in Norway: relational and theoretical, and the limitations of psychotherapy. Each of these themes could be understood as responses to dilemmas that emerged across many years of psychotherapy practice. In addition, each domain can be interpreted as reflecting a commentary and critique in relation to mainstream practice.

The findings of the present study are discussed first in relation to the results of the most directly comparable investigation, that of Levitt and Piazza-Bonin (2015a; b). The discussion then moves on to consider wider implications of the findings, possible directions for further research on the topic of therapist wisdom, and the limitations of the study.

There would appear to be three main ways in which findings from the present study reinforce themes identified by Levitt and Piazza-Bonin (2015a; b). The most striking area of similarity concerns the emphasis, in both samples, on the idea that therapist wisdom highlights the importance of being highly attuned to multiple aspects of the client-therapist relationship. In the present study, wisdom around the qualities of a constructive therapeutic relationship was documented through two themes: appreciation of the difference between "you" and "me" is needed to establish a relationship and a true dialogue, trustworthiness 
Wisdom

and real engagement are necessary and cultivating courage to "stand in the storm". Within Levitt and Piazza-Bonin (2015a,b), the corresponding themes were: valuing of relational attunement over decontextualized intervention enactment; being vulnerable and authentic allows us to appreciate the human experience; a wisdom model...emphasizes the role of the therapeutic relationship; and, wise therapists have emotional intelligence grounded in difficult life experiences to better understand how to work through painful and powerful emotions. Careful scrutiny, across both investigations, of sub-themes and interview quotes associated with these themes suggests that they would be highly likely to be contributing to a single category in a systematic qualitative meta-synthesis review exercise. This level of convergence suggests that, even if it is expressed in slightly different terms by therapists working in different social contexts, sensitivity to relational dynamics represents a core feature of the wise practice of therapy at this stage in the history of the professional.

A second area of convergence concerns the concept of therapist humility (Theme: "Wisdom arising from the struggle to resolve the dilemma of reconciling the ambition of therapy theory with the lived experience of client outcome"). In both studies, humility represented an essential element of therapist wisdom. A third way in which findings from the present study coincide with results from Levitt and Piazza-Bonin (2015a; b), refers to the way in which therapist wisdom was narrated by participants as a conscious reaction to, and rejection of, aspects of prevailing therapy practice. This contrast is apparent within many of the interview excerpts presented above. Within the Levitt and Piazza-Bonin (2015a; b) investigation, it was most salient in relation to participant accounts of how wisdom might be cultivated through training - we suggest that much of this material can be read as a profound critique of established educational practice within the profession.

Alongside these areas of convergence, there were also some areas of divergence between the present study and Levitt and Piazza-Bonin (2015a; b). In the present study, some 


\section{Wisdom}

participants talked about their struggles in coming to terms with what they experienced as over-theorized approaches to therapy, where the temptation to focus on being clever themselves may interfere with being helpful to clients, and about the significance of art and courage. These themes were not apparent in the analysis conducted by Levitt and PiazzaBonin (2015a; b). Conversely, the earlier investigation by Levitt and Piazza-Bonin (2015a; b) identified significant wisdom themes that did not emerge as significant themes in the present study, including the difference between intelligence and wisdom, and the value of collaboration, flexibility and humor. Nevertheless, these topics were not completely lacking in the present study. The difference between intelligence and wisdom may be related to the therapists' reflections about the potential conflict between being helpful and being clever. Collaboration seems to have been talked about indirectly by participants, in highlighting the importance of the relationship. However, it was only mentioned explicitly by three informants. Flexibility was mentioned explicitly by two informants, and indirectly by most of them, who reported that they had grown more tolerant over the years. Four informants explicitly mentioned the significance of humor as an important perspective in life and in therapy.

These differences may arise from contrasting aspects of the professional identities of therapists in the two samples. The therapists interviewed in the present study were predominantly psychodynamic in orientation, whereas the informants interviewed by Levitt and Piazza-Bonin (2015a; b) included mainly integrative therapists drawing from a variety of orientations. Also, differences in findings may have arisen due to the contrasting recruitment and interview strategies in the two studies. Finally, differences in findings may reflect contrasting cultural influences.

The notion that therapist wisdom represents a particular point in an endlessly churning cycle of knowledge-creation is consistent with the position of Baltes and Staudinger (2000) that: 
Wisdom

wisdom is a metaheuristic, that is, a heuristic that organizes, at a high level of aggregation, the pool (ensemble) of bodies of knowledge and commensurate, more specific heuristics that are available to individuals in planning, managing, and evaluating issues surrounding the fundamental pragmatics of life (p. 132).

This perspective is supported in the present study through comparison of the relationship between the knowledge themes that were identified, and the developments within the field of psychotherapy research. Courage, how theories are used, you/me differentiation, and drawing on art to maintain a creative means of thinking about relationships, are topics that have not been explored in the literature to any great extent. By contrast, the theme of professional self-doubt and humility, which also emerged as a wisdom theme in the present study, is currently an emergent topic that has begun to receive attention through large-scale research studies (Nissen-Lie, Monsen, \& Rønnestad, 2010; Nissen-Lie, Rønnestad, Høglend, Havik, Solbakken, Stiles, \& Monsen, 2015).

The extensive discussion generated in interviews, around the role of theory in therapy, appeared to reflect a tension between acknowledging the important role of theory, while at the same time wishing to remain close to the experience of the client rather than interpreting that experience through a fixed theoretical lens. These accounts also appeared to reflect a tension within the profession between approaches to therapy based on purist, singular and coherent theoretical systems, as against the tendency in many practitioners to adopt a more integrative, pragmatic and theoretically pluralist approach. The formulation that "theories become more helpful the more you get to know them", even though "there is always another theory" represents a wise standpoint that acknowledges both the value of commitment to a theory, alongside open-ness to theoretical diversity. In effect, these senior therapists were not choosing between adherence to a single-school theoretical framework, or to some kind of 


\section{Wisdom}

model of theoretical eclecticism/integration. Instead, they were implying that it was possible to do both at the same time. This finding is consistent with both the idea that experienced therapists "metabolize" theory in terms of integrating it into their way of being in the world (Betan \& Binder, 2000), the notion that they implement a "postmodern epistemology of practice" that is skeptical of the value of singular theoretical positions (Polkinghorne, 1992), and the extensive evidence that experienced clinicians integrate techniques and ideas from a plurality of therapy approaches (see, for example, Lampropoulos \& Dixon, 2007; Thoma \& Cecero, 2009). . The rich material offered by this Norwegian sample around theoretical wisdom can be viewed as a consequence of the professional culture within which research participants have worked; the struggle to retain the theoretical coherence and power of psychoanalytic theory, while making space for other theoretical perspectives, has been a major preoccupation in psychology in Norway over the last 40 years.

Almost all of the participants in this sample made use of art and literature as a means of developing a creative therapeutic imagination. The arts can complement what can be learned from research and textbooks. Human life and struggles have several facets and nuances. Knowledge and understanding is not always reducible to language. Eisner (2008) describes how knowledge arising from art is related to understanding through empathy, and openness to being moved. Engagement with art can also have the effect of problematizing traditional conclusions and providing fresh perspectives, so that habitual ways of thinking do not totally dominate our reactions. Art can provide new ways with which to perceive and interpret the world, ways that make vivid realities that would otherwise go unknown: "in addressing what is subtle but significant, the arts develop dispositions and habits of mind that reveal to the individual a world he or she may not have noticed but that is there to be seen if only one knew how to look" (Eisner, 2008, p. 11). 
Wisdom

The arts, especially music, occupy non-discursive form of knowledge (Langer, 1957) that provides ways to represent the structure of forms of feeling: "works of art enable us to know something about feeling that cannot be revealed in literal scientific statement" (Eisner, 2008, p. 8). Art address the qualitative nuances of situations. Engagement in art makes it possible to develop a deeper awareness of fine distinctions in meaning and action. In these respects, an active interest in art can be helpful for therapists in cultivating empathy and staying open to new understandings of a client and his/her struggles. These themes are consistent with the findings of Rouse, Armstrong and McLeod (2015), who examined the ways in which therapists who had a previous or concurrent career as artists, were able to make use of art-based ways of thinking in their work with clients.

Within the findings of the present study, the difference between "you" and "me", as a precondition for dialogue, emerged as a significant wisdom theme. This idea does not appear to have been extensively explored within the research literature, but is consistent with ideas of the philosopher Martin Buber (1937) and with contemporary theory around the role of dialogue in psychotherapy. For example, Schmid (2007) has argued that an essential aspect of being human involves understanding and accepting that there exists a collective or shared human reality that transcends the individual perceptions or lives of any one of us. From this perspective, rooted in the humanistic-existential tradition in psychotherapy, effective therapy requires a capacity to engage in dialogue in which each participant can be fully present to the other.

The concept of courage is rarely mentioned in psychotherapy research, and "courage" does not seem to be used as a searchable key word in research databases or textbooks. However, therapist courage comprises a key concept within functional analytic psychotherapy (Tsai, 2008), and has been addressed by several writers within the psychoanalytic literature, who have acknowledged that therapists need to be brave to face unknown, unpredictable and 
Wisdom

sometimes scary parts of their clients and their own inner life (Akhtar, 2013; Ericson, 1979; Jacobs, 2008; Levine, 2006; Poland, 2007; 2008; Rosenbaum, 2009). For example, Jacobs (2008) described how he struggles to overcome his own prejudices and preferences in his work with a deeply conflicted homosexual man who was married to a woman. The deep roots of an awareness of therapist courage within the psychoanalytic tradition are highlighted by Poland (2008), in the form of a letter from Freud to Ferenczi where he wrote that "selfcriticism is not a pleasant gift, but it is, next to my courage, the best thing in me". As Poland (2008) interprets Freud's statement, it is about the willingness of the clinician to expose and explore whatever unfolds clinically heedless of the personal risks that may ensue. Our sample had basically a psychodynamic orientation and seemed to be familiar with thinking about courage as part of the psychotherapeutic relationship.

Courage can also be viewed from a philosophical angle. Courage is relevant when dealing with moral issues, which are of huge relevance for the psychotherapeutic relationship. Miller (2004) is concerned with the necessity of relating to moral issues and to the clients' suffering to be able to help. This is often a challenging task since people tend to avoid suffering. Practitioners need to learn to attend to patients' suffering, despite the pain it may evoke.

Our experience in carrying out this study has helped us to appreciate the degree to which wisdom is a contextualized accomplishment. We suggest that the "wise" statements made by the therapists who we interviewed, and the participants in the Levitt and PiazzaBonin (2015a; b) study, were not utterances that could be regarded as eternal truths. Instead, they functioned as a "metaheuristic", by means of the application of well-established characteristics of wisdom (e.g., tolerance of uncertainty, contextualism, values, relativism, and adopting a long-term perspective) in response to current issues and choice-points within the domain of professional knowledge. In other words, their wisdom could be regarded as a 
Wisdom

situated form of communication, within the interview situation, directed at interviewers and ultimately readers who were more immersed in current thinking or common-sense assumptions about how to understand the nature of therapy.

This way of thinking about therapist wisdom opens up a number of implications around research methodology and possible lines of direction of future development of research on therapist wisdom. We will need to know more about how therapists act wisely in meetings with clients. It seems plausible to suppose that therapists could be observed to behave in ways that reflected professional self-doubt/modesty, art-informed sensibility, and courage. It may be that these ways of being may function as "metaheuristics" that can be modeled to clients and which clients can then internalize and apply in their own lives. From this standpoint, the wisdom strategies developed within "wisdom therapy" (Lieberei \& Linden, 2011; Linden et al., 2011) may be just the tip of the iceberg. It is also possible that the enactment of wisdom metaheuristics may constitute a central attribute of highly effective therapists.

A final point we would like to make is that, although the form of thematic analysis used in this study has the effect of identifying discrete and separate themes, our sense was that many of these themes were interconnected in the stories told by the therapists in the study. When they talked, what they said appeared to emerge from an implicit set of core virtues: modesty, imagination and courage. As highlighted in philosophical writing on this topic, wisdom is not just about resolving dilemmas, but also relates to the wish to do so in a manner that contributes to the common good. Wisdom is not the only strategy that is used by therapists (and others) to transcend or resolve fundamental human dilemmas. Courage, imagination and modesty, along with wisdom, function as higher-order virtues that would appear to be equally significant. The inter-relatedness of these attributes is evident when 
Wisdom

describing real-life examples of wisdom. For instance, Yang (2013) used events in the life of Mother Theresa to exemplify different aspects of wisdom. This line of reflection returns to the idea of professional knowledge, introduced at the start of the paper. A key characteristic of therapist wisdom is that it represents an expression of humanistic values in the context of professional work (see, for example, Hansen, 2012; Miller, 2004).

\section{Limitations}

When considering the implications of these findings, it is necessary to take account of the limitations, exploratory intention, and purposefully contextualized nature of the study.

Participants were not specifically primed or probed in respect of wisdom themes. It is possible that a more wisdom-focused interview strategy, that invited participants to reflect on learning arising from practice-based dilemmas, might have elicited further themes and domains. It may be that the use of constructs from theories of wisdom could have been deployed as sensitizing concepts (Bowen, 2006) in way that could have enabled a more nuanced interpretation of the data. Despite our efforts to be transparent in our presentation of findings, and to open our analysis to external challenge, it is undoubtedly the case that the findings have to some extent been shaped by our assumptions and pre-understandings. While the interviewer was known to some participants as a junior professional colleague in previous years, we could not find any evidence that this characteristic had influenced their responses to the interview. Nevertheless, it would be of interest in future research to compare our findings with interviews with senior therapists conducted by someone of the same age, or a researcher who was entirely outside the theory professional circle. It is also important, when exploring the meaning of the findings, to retain awareness of the fact that they arise from the experiences of a group of mainly psychodynamic therapists who spent their professional lives working in a society in which, in general, psychotherapy as a whole, and psychodynamic therapy in particular, have been highly valued. The snowball sampling method may have contributed to a relatively 
Wisdom

homogenous sample. Homogeneity also refers to the informants' ethnicity, which mirror that Norway used to be a very homogenous society when it comes to ethnicity.

A further limitation of the study arises from the nature of wisdom as a concept. Qualitative methodologies have largely evolved as strategies for investigating lived experience, such as the client's experience of therapy. By contrast, wisdom as a higher-order construct that cannot be directly observed, that possesses a high positive valence which, in some instances, may make informants cautious about attributing wisdom to their own ideas). In the studies by Levitt and Piazza-Bonin (2015a; b), therapists were directly asked about wisdom, whereas participants in the present study were asked to talk about their lives as therapists, and then sections of their accounts were inferred as providing evidence of wisdom. Each approach has advantages and disadvantages. It is only when further studies of therapist wisdom are available that the implications of different data collection strategies will become more fully understood. We believe that it is important for researchers to build on these exploratory self-report studies, and find ways to examine what wise therapists do in their sessions with clients.

\section{Conclusions}

Therapist wisdom can be viewed as a form of contextualized knowledge, which functions as a source of emergent insights that arise as responses to the limitations of prevailing ways of thinking, particularly around the experience of dilemmas associated with theory and practice. This conclusion suggests a number of potentially significant implications for practice. It may be valuable to develop further ways for senior therapists, or those regarded as possessing wisdom, to communicate their hard-earned professional insights within professional arenas. It may be helpful, in training programs, to introduce students to an understanding of the 
Wisdom

processes through which the knowledge base that guides their practice will continually evolve over the course of their careers. 
Wisdom

\section{References}

Akhtar, S. (2013). Good stuff. Courage, resilience, gratitude, generosity, forgiveness, and sacrifice. Lanham, Maryland: Rowman \& Littlefield.

Alvesson, M., \& Sköldberg, K. (2000). Reflexive methodology. New vistas for qualitative research. Los Angeles, CA: Sage.

Anderson, T., Ogles, B. M., Patterson, C. L., Lambert, M. J. \& Vermeersch, D. A. (2009). Therapist effects: Facilitative interpersonal skills as a predictor of therapist success. Journal of Clinical Psychology, 65, 755-768.

Baltes, P. B. (1993). The aging mind: Potential and limits. The Gerontologist, 33, 580-594

Baltes, P. B., Staudinger, U. M., Maercker, A., \& Smith, J. (1995). People nominated as wise: A comparative study of wisdom-related knowledge. Psychology and Aging, 10, 155166. B

Baltes, P. B., \& Staudinger, U. M. (2000). Wisdom. A metaheuristic (pragmatic) to orchestrate mind and virtue toward excellence. American Psychologist, 55, 122-136.

Baumann, K., \& Linden, M. (2008). Weisheitskompetenzen und weisheitstherapie. Verlag, Lengerich: Pabst.

Bergner, R.M. (2006). Many secure knowledge bases of psychotherapy. American Journal of Psychotherapy, 60, 215-231.

Betan, E.J., \& Binder, J, L. (2010). Clinical expertise in psychotherapy: how expert therapists use theory in generating case conceptualizations and interventions. Journal of Contemporary Psychotherapy, 40, 141-152.

Bowen, G. A. (2006). Grounded theory and sensitizing concepts. International Journal of Qualitative Methods, 5, 12-23 
Wisdom

Braun, V., \& Clarke, V. (2006). Using thematic analysis in psychology. Qualitative Research in Psychology, 3, 77-101.

Braun, V., Clarke, V., \& Rance, N. (2014) How to use thematic analysis with interview data. In Vossler, A. \& Moller, N. (Eds.), The Counselling \& Psychotherapy Research Handbook (pp. 183-197). London: Sage.

Buber, M. (1937). I and thou. Edinburgh, UK: T. \&. T. Clark

Chartas, N.D., \& Culbreth, J.R. (2001). Counselor treatment of coexisting domestic violence and substance abuse: A qualitative study. Journal of Addictions \& Counseling, 22, 211.

Christianson, C.L., \& Everall, R.D. (2009). Breaking the silence: School counsellors' experiences of client suicide. British Journal of Guidance \& Counselling, 37, 157-168.

Dlugos, R.F., \& Friedlander, M.L. (2001). Passionately committed psychotherapists: A qualitative study of their experiences. Professional Psychology: Research and Practice, 32, 298-304.

Dunnavat, B.R. \& Levitt, H.M. (2015). The development of wisdom in judicial decision making. The Humanistic Psychologist, 43, 1-23. doi: 10.1080/08873267.2014.993068

Eisner, E. (2008). Art and knowledge. In J.G, Knowles \& A.L. Cole (Eds.) Handbook of the arts in qualitative research. Perspectives, methodologies, examples and issues. (pp. 312). Thousand Oaks, CA: Sage.

Ericson, E.L. (1979). Moral courage and the regeneration of hope. Contemporary Psychoanalysis, 15, 338-344

Evans, T. (2015). Counselling skills for becoming a wise practitioner. Tools, techniques and 
Wisdom

reflections for building practice wisdom. London: Jessica Kingsley.

Fishman, D. B. (1999). The Case for a Pragmatic Psychology. New York: NYU Press.

Fox, C. (2011). Working with clients who engage in self-harming behaviour: experiences of a group of counselors. British Journal of Guidance \& Counselling, 39, 41-51.

Geller, J. \& Farber, B. (1993). Factors influencing the process of internalization in psychotherapy. Psychotherapy Research, 3, 166-180.

Geller, J.D. (2014). Adult development and the transformative powers of psychotherapy. Journal of Clinical Psychology, 70, 768-779.

Goldberg, C. (1992). The seasoned psychotherapist: Triumph over adversity. New York: W.W. Norton \& Co.

Gordon, P. (2000). Playing for time: A psychotherapist's experience of counselling young people. Psychodynamic Counselling, 6, 339-357

Hanna, F. J., \& Ottens, A. J. (1995). The role of wisdom in psychotherapy. Journal of Psychotherapy Integration, 5, 195-219.

Hansen, J.T. (2012). Extending the humanistic vision: toward a humanities foundation for the counseling profession. Journal of Humanistic Counseling, 51, 133-144.

Jacobs, T.J. (2008). On courage. Psychoanalytic Psychology, 25, 550-555

Jennings, L., \& Skovholt, T. (1999) The cognitive, emotional, and relational characteristics of master therapists. Journal of Counseling Psychology, 46, 3-11.

Jennings, L., Skovholt, T. M., Goh, M., \& Lian, F. (2013). Master therapists: Explorations of expertise. In M. H. Rønnestad \& T. M. Skohvolt (Eds.), The developing practitioner: 
Wisdom

Growth and stagnation of therapists and counselors (pp. 213-246). New York, NY: Routledge.

Karakurt, G., Dial, S., Korkow, H., Manfield, T., \& Banford, A. (2013) Experiences of marriage and family therapists working with intimate partner violence. Journal of Family Psychotherapy, 24, 1-16.

Karasu, T.B. (2001). Wisdom in the practice of psychotherapy. $2^{\text {nd }}$ edn. Northvale, N.J., Jason Aronson.

Kazdin, A.E. (1999). The meanings and measurement of clinical significance. Journal of Consulting and Clinical Psychology, 67, 332-339

Kuzel, A. (1999). Sampling in qualitative inquiry. In W. Miller \& B. Crabtree (Eds.), Doing qualitative research (pp. 33-45). Thousand Oaks, C.A.: Sage.

Lampropoulos, G.K., \& Dixon, D.N. (2007). Psychotherapy integration in internships and counseling psychology doctoral programs. Journal of Psychotherapy Integration, 17, 185-208. http://dx.doi.org/10.1037/1053-0479.17.2.185

Langer, S.K. (1957) Problems of art: Ten philosophical lectures. New York: Scribner

Lawrence, A.A., \& Love-Crowell, J. (2007). Psychotherapists' experience with clients who engage in consensual sadomasochism: a qualitative study. Journal of Sex \& Marital Therapy, 34, 67-85

Lave, J., \& Wenger E. (1991) Situated Learning: Legitimate Peripheral Participation Cambridge: Cambridge University Press.

Levine, S.S. (2006). Catching the wrong leopard: Courage and masochism in the psychoanalytic situation. Psychoanalytic Quarterly, LXXV, 533-556 
Wisdom

Levitt, H.M., \& Piazza-Bonin, E. (2015a). Wisdom and psychotherapy: Studying expert therapists' clinical wisdom to explicate common processes. Psychotherapy Research, DOI: $10.1080 / 10503307.2014 .937470$

Levitt, H.M., \& Piazza-Bonin, E. (2015b). The professionalization and training of psychologists: The place of clinical wisdom, Psychotherapy Research

Levitt, H.M., Pomerville, A., \& Surace, F.I. (2016). A qualitative meta-analysis examining clients' experiences of psychotherapy: a new agenda. Psychological Bulletin

Lieberei, B., \& Linden, M. (2011). Wisdom psychotherapy. In M. Linden, \& A. Maercker (eds). Embitterment. Societal, psychological, and clinical perspectives. (pp. 209-220). New York: SpringerWien

Linden, M., Baumann, K., Lieberei, B., Lorenz, C., \& Rotter, M. (2011). Treatment of posttraumatic embitterment disorder with cognitive behaviour therapy based on wisdom psychology and hedonia strategies. Psychotherapy and Psychosomatics, 80, 199-205.

Magnusson, E., \& Marecek, J. (2015). Doing interview-based qualitative research. Cambridge: Cambridge University Press

Marecek, J., Fine, M., \& Kidder, L. (1997). Working between worlds: Qualitative methods and social psychology. Journal of Social Issues, 53, 631-644.

McLeod, J. (2016). Using research in counselling and psychotherapy. London: Sage.

Miller, B. (2007). What creates and sustains commitment to the practice of psychotherapy? Psychiatric Services, 58, 174-176.

Miller, R. (2004). Facing Human Suffering: Psychology and Psychotherapy as Moral Engagement. Washington, DC: American Psychological Association. 
Wisdom

Miller, S.D., Hubble, M.A., Chow, D.L., \& Seidel, J.A. (2013). The outcome of psychotherapy: yesterday, today, and tomorrow. Psychotherapy, 50, 88-97.

Miller, S. D., Hubble, M. A., Chow, D., \& Seidel, J. (2015). Beyond measures and monitoring : realizing the potential of feedback-informed treatment. Psychotherapy, 52, $449-457$.

Nissen-Lie, H. A., Monsen, J. T., \& Rønnestad, M. H. (2010). Therapist predictors of early patient-rated working alliance: A multilevel approach. Psychotherapy Research, 20, 627-646.

Nissen-Lie, H.A., Rønnestad, M.H., Høglend, P.A., Havik, O.E., Ole Solbakken, A., Stiles, T,C., \& Monsen, J.T. (2015). Love yourself as a person, doubt yourself as a therapist? Clinical Psychology and Psychotherapy.

Orlinsky, D.E, \& Rønnestad, M.H. (2015). Psychotherapists growing older: a study of senior practitioners. Journal of Clinical Psychology, 71, 1128-1138.

Patton, M. Q. (2002). Qualitative research and evaluation methods. Thousand Oaks, C.A.: Sage.

Poland, W.S. (2007). Courage and morals. American Imago, 64, 253-259

Poland, W.S. (2008). “The best thing in me”. The analyst's courage in clinical practice. Psychoanalytic Psychology, 25, 556-559

Polanyi, M. (1958). Personal Knowledge: Towards a Post-Critical Philosophy. University of Chicago Press, Chicago

Polanyi, M. (1966/1983). The tacit dimension. Gloucester, MA: Peter Smith Publisher. 
Wisdom

Polkinghorne, D. E. (1992). Postmodern epistemology of practice. In S. Kvale (ed.) Psychology and Postmodernism. (pp. 146-165). London: Sage.

Revell, S., \& McLeod, J. (2016). Experiences of therapists who integrate walk and talk into their professional practice. Counselling and Psychotherapy Research, 16, 35-43.

Robbins, J.H. (2006). A psychotherapist retires. Women \& Therapy, 29:1-2, 189-203

Rosenbaum, M. S. (2009). Dare to be human. A contemporary psychoanalytic journey. New York: Routledge

Rouse, A., Armstrong, J., \& McLeod, J. (2015). Enabling connections: Counsellor creativity and therapeutic practice. Counselling and Psychotherapy Research, 15, 171-179.

Rønnestad, M. H., \& Skovholt, T. M. (2013). The developing practitioner: Growth and stagnation of therapists and counselors. New York: Routledge.

Råbu, M., Moltu, C., Binder, P.E., Mcleod, J. (2016). How Does Practising Psychotherapy Affect the Personal Life of the Therapist? A Qualitative Inquiry of Senior Therapists' Experiences. PsychotherapyResearch, 26, 737-749

Scaturo, D. J., \& McPeak, W. R. (1998). Clinical dilemmas in contemporary psychotherapy: the search for clinical wisdom. Psychotherapy, 35, 1-12.

Schmid, P. E. (2007). The anthropological and ethical foundations of person-centred therapy. In Cooper, M., O’Hara, M., Schmid, P.F., \&Wyatt, G. (eds) The Handbook of Personcentred Psychotherapy and Counselling. (pp. 30-46). Ross-on-Wye: PCCS Books.

Siegel, R.D. (2012). The wise psychotherapist. In C.K. Germer \& R.D. Siegel (Eds). Wisdom and Compassion in Psychotherapy. Deepening mindfulness in clinical practice. (pp. 138-153). New York: Guilford Press. 
Wisdom

Staudinger, U.M. (2008). A psychology of wisdom: history and recent developments. Research in Human Development, 5, 107-120.

Staudinger, U. M. (1999). Older and wiser? Integrating results on the relationship between age and wisdom-related performance. International Journal of Behavioral Development, 23, 641-664.

Sternberg, R.J. (1998). A balance theory of wisdom. Review of General Psychology, 2, 347365.

Thoma, N. C., \& Cecero, J. J. (2009). Is integrative use of techniques in psychotherapy the exception or the rule? Results of a national survey of doctoral-level practitioners. Psychotherapy, 46, 405-417.

Tsai, M., Kohlenberg, R. J., Kanter, J. W., Kohlenberg, B., Follette, W. C., \& Callaghan, G. M. (2008). A guide to Functional Analytic Psychotherapy: Awareness, courage, love, and behaviorism. New York: Springer.

van Rooij, A.J., Zinn, M.F., Schoenmakers, T.M., \& van de Mheen, D. (2012). Treating internet addiction with cognitive-behavioral therapy: a thematic analysis of the experiences of therapists. International Journal of Mental Health \& Addiction, 10, 69-82.

Wenger, E. (1998). Communities of Practice: Learning, Meaning, and Identity, Cambridge: Cambridge University Press.

Yang, S. (2013). Wisdom and good lives: A process perspective. New Ideas in Psychology, 31, 194-201. 
Wisdom 


\section{Appendix: The interview guide}

- What have your experiences as a therapist provided you with - as a person and as a practitioner? What have been the costs? Please think about concrete therapies that have contributed to mould you as a therapist and which have possibly interfered with your life as such.

- What have been the hardest parts of working as a therapist? How do you think this have affected you? Please think about concrete events or situations.

- Has your work as a psychotherapist affected your personal/close relationships? If so: In what way? (Relationships with, for instance, spouse, children, close friends, others) Are there special experiences that stand out?

- What made you become a therapist? Did you ever think of other possibilities?

- In addition to everything you have learned as a professional, what personal qualities have been important in your work?

- Have any of your personal characteristics been problematic?

- What have supervision and personal therapy meant to you?

- Please tell me about how your view of therapy has changed during the years you have worked.

- What do you think therapy can offer when it comes to change and development for clients? Has your view changed over the years?

- What did you consider as the most important qualities for a therapist when you started to work? Has your view changed? How?

- How would you describe "a good therapist"?

- What are your thoughts about the client's own contribution in change processes? Has your view changed? How?

- What do you think therapists could do to take care of themselves? 
Wisdom

- Is there anything important that I have not asked about? 